\title{
Educación: un derecho de los pueblos originarios
}

\author{
Por Simeone Iván Alejandro
}

\section{Resumen}

El presente trabajo que he decidido nombrar "Educación: un derecho de los pueblos originarios" es realizado en el marco del Seminario de grado "La Justiciabilidad de los Derechos Sociales. Los estándares internacionales en la justicia bonaerense". Se elabora un estudio sobre el derecho a la educación reconocido a los pueblos originarios. Partiendo de su conceptualización, se elabora un análisis de la normativa aplicable al derecho a la educación, desde los tratados internacionales hasta la normativa local de la Provincia de Buenos Aires, para contrastar esa construcción ideal de la educación con la realidad vigente a partir de las falencias en su ejecución, fundamentalmente por la política educativa, en torno a los pueblos originarios.

Palabras Claves: educación intercultural, Estado, pueblos originarios, obligaciones, política.

\section{Introducción}

La educación intercultural bilingüe (EIB) es un modelo educativo que tiene como propósito la transmisión y participación de los conocimientos, costumbres y tradiciones ancestrales. En su aplicación, la EIB se encuentra íntimamente ligada a las contingencias sociales que viven los pueblos originarios y forma parte de un cúmulo de derechos humanos. Esos derechos reconocidos, tanto en los tratados internacionales como en las normativas locales, deben ser garantizados por los Estados a través de sus políticas públicas.

La característica principal del derecho a la educación a los pueblos originarios, es que debe darse en el marco del respeto por la identidad cultural, sin discriminación, acorde a las creencias y al lenguaje nativo de las comunidades aborígenes. Por lo tanto, la educación indígena cuenta de dos ejes centrales que son la interculturalidad y el bilingüismo, pero ambos se ven amenazados por la globalización educativa.

Para analizar esta problemática es necesario mencionar sus causas. Una de ellas es la falta de implementación continua y a gran escala, de programas estatales educativos interculturales en la región de Latinoamérica. En Argentina, “(...)hay una profunda escisión entre las declaraciones de derecho y la práctica política y social (Diez, 2004:191)”

Otra de las causas, es la falta de acceso y reclamos a los órganos de justicia por parte de los pueblos originarios, que responde a su incipiente reconocimiento de derechos en las constituciones nacionales y en corolario, el desconocimiento que tienen de ellos.

Por las razones esgrimidas, la EIB carece de calidad y alcance, impidiendo la transmisión de conocimientos indígenas y, esa consecuente desvalorización, viene acompañada de pobreza cultural, detrimento de la lengua y, lo que no es poco, pérdida de su identidad. 


\section{Objetivos perseguidos de esta investigación}

Analizar, en base a tres fallos de la Corte Interamericana de Derechos Humanos relacionados al derecho a la educación de los pueblos originarios, el grado de implicancia que adquirirían en el futuro para Argentina.

Diferenciar la actividad de los tres poderes del Estado (Legislativo, Judicial y Ejecutivo) y la influencia que ejercen sobre el derecho a la educación de los pueblos originarios.

Verificar, en nuestro universo de estudio, si es posible la realización plena de la Educación Intercultural Bilingüe en Argentina.

La estrategia empleada en el presente trabajo fue comenzar por el marco conceptual y la importancia del derecho a la educación, en interdependencia con otros derechos humanos. Son fundamentales las "4 A" de la Relatora de Las Naciones Unidas sobre el derecho a la educación, ya que sirve de base para entender los objetivos que debe tener la política educativa de los estados.

Asimismo, se realizó un análisis histórico normativo desde el enfoque educacional, de los derechos reconocidos en Argentina a los pueblos originarios que llevó a la construcción teórica de la Educación Intercultural Bilingüe.

Han sido utilizadas estadísticas de la Provincia de Buenos Aires (y en comparación con el plano nacional) para tener un reflejo de la situación actual y entender aún más la problemática. Además, fueron consideradas las críticas del investigador del Comité de Derechos Humanos en la última visita a nuestro país.

Fue necesario entender el marco jurídico del derecho a la educación y las obligaciones asumidas internacionalmente por parte del Estado argentino para adentrarse en las falencias del mismo, a la luz de la Observación General N³ del Comité de Derechos Humanos, en asegurar el derecho a la educación en las comunidades aborígenes. A su vez, se utilizaron fallos jurisprudenciales de la Corte Interamericana de Derechos Humanos donde varios países tuvieron sentencias adversas, por el incumplimiento y la falta de medidas protectorias de los derechos humanos. También, se hizo hincapié en la falta de jurisprudencia de casos relacionados con el derecho a la educación de los pueblos originarios en nuestro país.

Culmina la investigación evaluando si los objetivos planteados en el comienzo fueron alcanzados y que reflexiones personales se pueden sacar al respecto.

\section{II) El derecho a la educación}

\section{Conceptualización}

En la actualidad, acercar una definición del derecho a la educación no es tarea sencilla, debido a que, a lo largo de los años, el concepto ha ido evolucionando por el avance del derecho internacional para acercar respuestas a las problemáticas sociales de los países. Brindar una educación accesible, de calidad y en igualdad de oportunidades para toda la sociedad son principios del derecho a la educación que funcionan como una herramienta para lograr la erradicación de la pobreza. Por eso, el derecho a la educación se relaciona a su vez con otros derechos humanos, como el derecho a la salud, trabajo, igualdad, no 
discriminación, participación ciudadana, derechos políticos y libertad de expresión, entre otros. En resumen, una persona con una formación integral educativa de calidad acrecentará sus oportunidades a conseguir un empleo mejor, y/o desarrollar una actividad profesional, obtener fluidez en su comunicación y conocimientos, tanto para la defensa de sus derechos como también para el desarrollo pleno de su humanidad.

Para que las personas puedan desarrollarse a lo largo de todo un proceso educativo es necesario el acompañamiento de las políticas públicas y el rol del Estado, como también de las provincias. La Convención de los Derechos del Niño dice en su art. 29 inc. A que los Estados deben velar por el desarrollo de la personalidad, aptitudes y desarrollo psico-físico del niño hasta el máximo de sus posibilidades. Sobre dicho artículo se realiza la Observación General $\mathrm{N}^{\circ} 1$ de la Convención en el año 2001, que dice

(...) el objetivo principal de la educación es el desarrollo de la personalidad de cada niño, de sus dotes naturales y capacidad, reconociéndose el hecho de que cada niño tiene características, intereses y capacidades únicas y también necesidades de aprendizaje propias (...) (Comité de los Derechos del Niño, 2001).

A su vez, en el plano del derecho internacional, la Observación General № 13 del Comité de Derechos Económicos, Sociales y Culturales, establece que “...la educación es un derecho humano intrínseco y un medio indispensable de realizar otros derechos humanos.....Asimismo, destaca que

(...) la educación desempeña un papel decisivo en la emancipación de la mujer, la protección de los niños contra la explotación laboral, el trabajo peligroso y la explotación sexual, la promoción de los derechos humanos y la democracia, la protección del medio ambiente y el control del crecimiento demográfico. Está cada vez más aceptada la idea de que la educación es una de las mejores inversiones financieras que los Estados pueden hacer, pero su importancia no es únicamente práctica pues dispone de una mente instruida, inteligente y activa, con libertad y amplitud de pensamiento, lo que es uno de los placeres y recompensas de la existencia humana (...) (Comité de los Derechos del Niño, 2001).

Para finalizar la conceptualización, el Foro Mundial sobre la Educación Dakar (Senegal) del año 2000, describe que

(... ) la educación es un derecho humano fundamental, y como tal es un elemento clave del desarrollo sostenible y de la paz y estabilidad en cada país y entre las naciones, y, por consiguiente, un medio indispensable para participar en los sistemas sociales y económicos del siglo XX(...) (PIDESC, 1976).

Asimismo, la Conferencia Mundial de Derechos Humanos establece que (...) la educación en materia de derechos humanos y la difusión de información adecuada, sea de carácter teórico o práctico, desempeñan un papel importante 
en la promoción y el respeto de los derechos humanos de todas las personas sin distinción alguna por motivos de raza, sexo, idioma o religión y debe integrarse en las políticas educativas en los planos nacional e internacional(...) (Conferencia Mundial de los Derechos Humanos, 1993).

\section{a) Obligaciones de los Estados}

El artículo 2 del Pacto Internacional de Derechos Económicos, Sociales y Culturales (en adelante el PIDESC) deja al arbitrio de los Estados Partes interesados la elección de medidas, sobre todo legislativas, hasta el máximo de los recursos de que disponga y en forma progresiva la aplicación del Pacto en sus territorios. Además, deben garantizar el cumplimiento de los derechos "sin discriminación alguna por motivos de raza, color, sexo, idioma, religión, opinión política o de otra índole, origen nacional o social, posición económica, nacimiento o cualquier otra condición social..." (PIDESC, 1976).

El Estado debe respetar, proteger y cumplir los derechos sociales, entre ellos, el derecho a la educación, lo que incluye, a su vez, dentro de la faceta de cumplir, la de facilitar y proveer.

He de aquí que el Comité del Pacto de los Derechos Económicos, Sociales y Culturales, en reiteradas oportunidades, menciona que el derecho a la educación reconocido en el Pacto es una imposición al Estado de obligaciones de comportamiento y resultado.

Por lo tanto, el Estado debe evitar restringir o limitar el derecho a la educación por sus propias acciones o medidas. También, debe proteger que terceros interfieran en el ejercicio de este derecho y establecer medidas sancionatorias, utilizando principalmente la actividad legislativa.Además, el Estado debe tomar medidas positivas para que los individuos o comunidades puedan gozar del derecho a la educación y,en caso de que no puedan facilitárselos por sus propios medios, el Estado es quien debe brindarle la asistencia suficiente.

\section{b) Esquema de las “4 A"}

Adicionalmente a las obligaciones de los Estados (descriptas en el título anterior), la ex Relatora Especial sobre el Derecho a la Educación de las Naciones Unidas, Katarina Tomaševski, propuso un esquema conocido como las " 4 A",en materia de PIDESC, que sonavailability (disponibilidad), accesibility(accesibilidad), acceptability (aceptabilidad) y adaptability (adaptabilidad).Mediante este esquema, se puede medir el grado de eficacia del derecho. Las cuatro características fundamentales, en interrelación con el interés superior del niño, deben ser las consideraciones prioritarias

\section{Disponibilidad}

La disponibilidad incluye dos obligaciones gubernamentales distintas: el derecho a la educación como un derecho civil y político requiere que el gobierno permita a agentes no gubernamentales establecer instituciones escolares; y el derecho a la educación como un derecho social y económico requiere que el gobierno las establezca, financie o combine estos u otros medios para asegurar que la educación esté disponible (Tomaševski, 2001:13). 
La disponibilidad se refiere a que las escuelas primarias deben estar físicamente presentes en el territorio estatal y ser aptas para utilizarse; debe haber suficiente cantidad y estar distribuidas adecuadamente en la jurisdicción estatal. También, se refiere a la existencia de medidas y condiciones que garanticen que todas las personas fuera de la edad escolar que no hayan terminado la secundaria puedan hacerlo.

\section{Accesibilidad}

Todas las personas deben tener acceso a los establecimientos escolares, sin discriminación alguna. La accesibilidad tiene tres dimensiones que se superponen: no discriminación, accesibilidad física y accesibilidad económica.

Principio de No Discriminación: todas las personas deben tener acceso a la educación, especialmente los grupos más vulnerables. Al respecto, considero fundamental traer la definición en materia educacional de la Convención relativa a la Lucha contra las Discriminaciones en la Esfera de la Enseñanza al decir, en su art.1, que se considerará discriminación

(...) toda distinción, exclusión, limitación o preferencia, fundada en la raza, el color, el sexo, el idioma, la religión, las opiniones políticas o de cualquier otra índole, el origen nacional o social, la posición económica o el nacimiento, que tenga por finalidad o por efecto destruir o alterar la igualdad de trato en la esfera de la enseñanza y, en especial: a. Excluir a una persona o a un grupo del acceso a los diversos grados y tipos de enseñanza; b. Limitar a un nivel inferior la educación de una persona o de un grupo; c. A reserva de lo previsto en el artículo 2 de la presente Convención, instituir o mantener sistemas o establecimientos de enseñanza separados para personas o grupos; o d. Colocar a una persona o a un grupo en una situación incompatible con la dignidad humana (...) (Convención relativa a la Lucha contra las Discriminaciones en la Esfera de la Enseñanza, 1960/S/A)

Los niños excluidos, vulnerables, marginados y perjudicados deben gozar siempre de oportunidades igualitarias al acceso a educación primaria de calidad.

La accesibilidad física se relaciona con eliminar todas las barreras físicas que le impidan al alumno acudir al establecimiento educativo ya sea, por la ubicación geográfica o por la tecnología, si se trata de educación a distancia. En el primer caso, es importante brindar el transporte y no solo asegurar la gratuidad, sino también adecuar estratégicamente la necesidad del individuo o comunidad. El segundo caso se relaciona con el aporte de instrumentos técnicos acorde a la enseñanza. Asimismo, los edificios o casas educativas deben adaptarse con rampas y toda construcción edilicia para que el alumno con discapacidad no pueda ver vulnerado su derecho a aprender por no poder concurrir a clase.

La accesibilidad económica se refiere a que la educación debe ser asequible para todos. Aquí ingresan la obligatoriedad global de que las escuelas en su nivel primario sean gratuitas y en sus niveles superiores (en nuestro país el nivel secundario es obligatorio y gratuito según 
Ley de Educación Nacional 26.026),implementen programas o becas que permitan saltear los obstáculos económicos para la formación profesional de niños, adolescentes y adultos.

\section{Aceptabilidad}

La aceptabilidad significa que la educación debe ser pertinente, culturalmente apropiada y de calidad, y conforme con el interés superior del niño, incluyendo las normas mínimas de salud y seguridad y los requisitos profesionales de los docentes, que deben ser establecidos, monitoreados y aplicados por el gobierno.

La aceptabilidad para los padres se relaciona con su libertad para elegir la educación de sus hijos, sin interferencia, conforme con sus convicciones religiosas, morales o filosóficas.

\section{Adaptabilidad}

Este concepto se relaciona con que la escuela se adapte al alumno acorde a las condiciones y necesidades de la comunidad donde vive, adaptándose el plan de enseñanza al entorno social del chico. Por ende, se revirtió una opinión predominante que obligaba a los niños a adaptarse a la forma de educación que la escuela ofrecía. Este es el caso de algunos niños discapacitados, niños con necesidades especiales para el aprendizaje o niños que trabajan o están encarcelados. Si ellos no pueden asistir a la escuela, la educación debe ir a donde sea que ellos estén.

Lograr la asistencia regular del alumno y la no deserción escolar son claves en las que debe enfocarse un Estado, dentro de la política educativa. Las prestaciones adecuadas, continuas y progresivas ayudan al alumno a concurrir regularmente a los establecimientos educativos y, sobre todo, a protegerlo de toda discriminación que pudiera sufrir e hiciera que abandone la escuela. Compone una de las obligaciones del Estado la lucha por la discriminación, acorde al art. 13 del PIDESC, al igual que las medidas positivas al derecho a la educación. Otros dos principios en materia obligacional lo componen los principios de progresividad (art. 26 PIDESC) y no regresividad de los derechos humanos del Pacto mencionado. Sobre estos, las medidas que adoptan los Estados Partes en favor de los derechos humanos no pueden implicar un retroceso en su reconocimiento, sino que siempre se debe mirar hacia adelante y asumir compromisos en las políticas públicas.

\section{III) Marco jurídico}

Se enunciarán los tratados, constituciones y leyes de mayor relevancia que aportan los cimientos más fuertes sobre el derecho a la educación. A su vez, se destacarán los principios y fines de cada uno.

\section{a) Normativa Internacional}

Convención sobre los Derechos del Niño 
Art. 28

- Enseñanza primaria obligatoria y gratuita.

- Fomento de la educación secundaria, general y profesional.

- Accesibilidad a la enseñanza superior y todas las cuestiones educacionales.

- Adopción de medidas estatales para la concurrencia regular y evitar la deserción escolar del alumno.

Art. 29

- Velar por el desarrollo integral de la personalidad del niño.

- Enseñanza de derechos humanos.

- Respeto por la identidad cultural y raíces del niño.

- Respeto por el medio ambiente.

Pacto Internacional de Derechos Económicos, Sociales y Culturales: Art. 13.

- Desarrollo de la personalidad y dignidad humana.

- Respeto por los derechos humanos y por las libertades fundamentales.

- Respeto por la diversidad cultural.

- Enseñanza primaria obligatoria y gratuita.

- Implementación de medios para la gratuidad de la escuela secundaria e incluso niveles superiores.

- Implantar sistema de becas. Mejorar la formación del docente.

- Libertad de los padres de elegir la educación de sus hijos acorde a sus creencias.

Convención Americana sobre Derechos Humanos

(Pacto de San José y Protocolo de San Salvador)

Arts. 1 y 26

- Protección y desarrollo progresivo del derecho a la educación.

Declaración Americana de los Derechos y Deberes del Hombre Artículo XII

- Educación inspirada en principios de libertad, moralidad y solidaridad humana

- Utilidad de la educación para mejorar el nivel de vida.

- Igualdad de oportunidades.

- Gratuidad de la educación primaria.

Declaración Universal de Derechos Humanos

Art. 26 
- Gratuidad y obligatoriedad de la instrucción elemental.

- Fomentación del desarrollo de la persona humana.

- Respeto por los derechos humanos.

- Libertad de los padres para elegir la educación de sus hijos

Convención Internacional sobre la Eliminación de todas las Formas de Discriminación Racial

Art. 5.

- Asegurar un nivel óptimo de independencia y de calidad de vida.

- Eliminación de prejuicios, estereotipos y otras actitudes.

a) Normativa Nacional y Provincial

Constitución de la Nación Argentina

Art. 5, 14, 75 inc. 19

- Obligatoriedad de la escuela primaria en cada provincia.

- Derecho de todos los habitantes a enseñar y aprender

- Principio de gratuidad.

- Obligaciones del Congreso de sancionar leyes en materia de educación que obliguen al Estado a proporcionar igualdad de oportunidades y posibilidades (no discriminación), gratuidad, equidad y educación autónoma y autárquica, incluso en sus niveles superiores.

\section{Constitución de la Provincia de Buenos Aires.}

Art. 36. Artículo 198 y subs.

- Igualdad de oportunidades y posibilidades.

- Formación integral. Respeto y libertad de conciencia.

- Gratuidad de la educación pública en todos sus niveles (incluso universidades). Obligatoriedad en el nivel básico.

- Calidad educativa equitativa.

Ley Educación Nacional 26026:

- Educación y conocimiento como bien público, derecho personal y social.

- Promoción de una educación integral, permanente y de calidad.

- Principios de igualdad, gratuidad y equidad.

- Calidad educativa. Integralidad.

- Respeto de valores éticos y democráticos. 
- Diversidad cultural. Integración regional.

- Educación inclusiva.

- No discriminación de género o cualquier otro tipo.

- Accesibilidad.

- Cultura del trabajo.

- Libre circulación del conocimiento. Estimular la participación ciudadana.

- Adaptabilidad a las nuevas tecnologías y formas de comunicación.

- Educación especial a las personas con discapacidades provisorias y temporales.

- Respeto a la identidad cultural y lenguas de las comunidades indígenas. Educación multicultural.

- Programas de enseñanza con valores y formación en todas las ciencias y disciplinas.

Además, es importante mencionar que establece para la educación:

- Presupuesto mínimo del (6 \%) del Producto Interno Bruto (PIB).

Ley Provincial 13688:

- Prioridad provincial y política de Estado.

A cargo de la Dirección General de Cultura y Educación:

- Provisión, garantía y supervisión de una educación, integral, inclusiva, permanente y de calidad para todos. Mecanismos y procedimientos para asegurar el derecho a la educación.

- Incorporación de personal especializado para trabajar en conjunto con los docentes de la escuela común.

- Cobertura de las instituciones educativas especiales; transporte; recursos técnicos y materiales, entre otras.

- Obligatoriedad escolar desde el nivel inicial hasta terminar la secundaria.

La ley asimila a la Convención de las Naciones Unidas sobre los Derechos del Niño estos principios:

- Gratuidad de la educación pública.

- Interculturalidad en la formación.

- Disposición del acceso libre y gratuito a la información pública de los datos estadísticos educativos.

c) Declaración de la ONU sobre los Derechos de los Pueblos Indígenas: carácter no vinculante

Adoptada en la Asamblea General de las Naciones Unidas el 13 de septiembre de 2007, la Declaración de las Naciones Unidas sobre los Derechos de los Pueblos Indígenas es el instrumento internacional para la protección de los derechos individuales y colectivos de los pueblos indígenas más importante de los últimos tiempos. Aquí, se les reconoce a las familias 
indígenas su rol primordial en las responsabilidades por la crianza, la formación, la educación y el bienestar de sus niños, niñas y adolescentes y destaca el derecho a su identidad cultural como descendientes de pueblos originarios. Es adoptada por una mayoría 144 Estados a favor (entre ellos Argentina), 4 votos en contra (Australia, Canadá, Nueva Zelanda y Estados Unidos de América) y 11 abstenciones (Azerbaiyán, Bangladesh, Bután, Burundi, Colombia, Georgia, Kenia, Nigeria, La Federación Rusa, Samoa y Ucrania).

Les acerco, en el marco de la Asamblea, la opinión de Les Malezer sobre la Declaración

La Declaración no representa solamente el punto de vista de las Naciones Unidas, ni representa solamente el punto de vista de los pueblos indígenas. Es una Declaración que combina nuestras visiones e intereses y que establece un marco para el futuro. Es una herramienta para la paz y la justicia que se basa en el reconocimiento y respeto mutuo (Les Malezer, 2007).

El proyecto de Declaración es un documento largo y complejo que contiene un preámbulo y 45 artículos, y está dividido en nueve secciones. Los artículos que desarrollan el derecho a la educación de los pueblos originarios son los siguientes:

\section{Artículo 14}

Inc.1. Los pueblos indígenas tienen derecho a establecer y controlar sus sistemas e instituciones docentes que impartan educación en sus propios idiomas, en consonancia con sus métodos culturales de enseñanza y aprendizaje.

Inc.2. Los indígenas, en particular los niños, tienen derecho a todos los niveles y formas de educación del Estado sin discriminación.

Inc.3. Los Estados adoptarán medidas eficaces, conjuntamente con los pueblos indígenas, para que las personas indígenas, en particular los niños, incluidos los que viven fuera de sus comunidades, tengan acceso, cuando sea posible, a la educación en su propia cultura y en su propio idioma.

\section{Artículo 15}

Inc.1. Los pueblos indígenas tienen derecho a que la dignidad y diversidad de sus culturas, tradiciones, historias y aspiraciones queden debidamente reflejadas en la educación y la información pública.

\section{Artículo 17}

Inc. 2. Los Estados, en consulta y cooperación con los pueblos indígenas, tomarán medidas específicas para proteger a los niños indígenas contra la explotación económica y contra todo trabajo que pueda resultar peligroso o interferir en la educación de los niños, o que pueda ser perjudicial para la salud o el desarrollo físico, mental, espiritual, moral o social de los niños, 
teniendo en cuenta su especial vulnerabilidad y la importancia de la educación para empoderarlos.

La Declaración también condena la discriminación contra los pueblos indígenas, promueve la participación indígena en la toma de decisiones políticas que les atañen, al respeto de su autonomía y propias prioridades, en cuanto al desarrollo económico, social y cultural. La declaración estimula explícitamente las relaciones de cooperación entre los Estados y los Pueblos Indígenas.

Si bien, en materia obligacional para los Estados, la Declaración no es vinculante, como los tratados internacionales que hemos desarrollado, y, por lo tanto, no hay mecanismos para denunciar a los países miembros por incumplimiento, tiene una fuerza moral innegable, ya que muchos de los derechos consagrados han sido reconocidos anteriormente en tratados de derechos humanos. Por lo tanto, a la hora de evaluar el accionar de un Estado, no deja de aplicarle la presente Declaración por parte de los comités de derechos humanos.

\section{IV) La educación intercultural bilingüe en Argentina}

\section{a) Evolución normativa}

El debate sobre la problemática indígena a nivel global por la falta de reconocimiento de sus derechos humanos comenzó en la década del 80 en el marco del VIII Congreso Indigenista Interamericano realizado en México. En años posteriores, los primeros que adoptaron la normativa en Argentina para el reconocimiento de derechos humanos a las comunidades indígenas fueron las provincias de Formosa (1984), Salta (1986), Chaco (1987), Misiones (1989), Río Negro (1987) y Santa Fe (1991). A nivel nacional, el primer suceso relevante es en el año 1985 en el cual se promulgó la ley 23.302 denominada "Política Indígena y Apoyo a las Comunidades Aborígenes” que crea el Instituto Nacional de Asuntos Indígenas (INAI) como entidad descentralizada con participación indígena que dependerá en forma directa del Ministerio de Salud y Acción Social. En 1994, se reformó la Constitución Nacional y significó un hecho histórico para los pueblos indígenas, ya que lograron el reconocimiento de la existencia de "pueblos originarios" en suelo argentino.

Habiéndose reformado la Constitución, se comenzó a trabajar en proyectos educativos denominados Interculturales Bilingües. Entre 1997 y 1999, el Programa Plan Social Educativo, junto con la Resolución 107/99 del Consejo Federal de Educación, bajo el proyecto "Promoción de Propuestas Alternativas", se incorporan al anexo de la Resolución 63/67 los títulos de Profesor Intercultural Bilingüe Modalidad Indígena para la Educación Inicial y de Profesor Intercultural Bilingüe Modalidad Indígena para el Primero y Segundo Ciclo de la Educación General Básica. En los años 2000 y 2001, se lanzan nuevos programas para mejorar la calidad educativa en las comunidades indígenas.

En el plano internacional, en el año 2001, entra en vigor el Convenio 169 de la Organización Internacional del Trabajo sobre pueblos indígenas y tribales en países independientes. Este auge de reconocimiento de derechos a las comunidades indígenas significó la reforma de muchas constituciones en los países de Latinoamérica, excepto la de Chile. Además, en el año 2007, Argentina vota a favor de la Declaración de las Naciones Unidas en la Asamblea General $N^{\circ} 13$, cuyo objetivo fue preservar y fortalecer el derecho de 
los pueblos indígenas a regir sus propias instituciones, culturas y tradiciones y a trabajar por su desarrollo de acuerdo a sus aspiraciones y necesidades.

En Argentina, en el año 2004, se crea el Programa Nacional de Educación Intercultural Bilingüe (PNEIB) y, dos años después, mediante la Ley de Educación Nacional 26.026, art. 52, se incorpora a la modalidad del sistema educativo la Educación Intercultural Bilingüe para, conforme al art. 75 inc. 17 de la C.N., brindar una educación acorde a las pautas culturales, lengua, cosmovisión e identidad étnica, y todo aprovechamiento para mejorar la calidad de vida de los pueblos originarios.

\section{b) Objetivos}

Ampliar normativamente los derechos mínimos reconocidos por las leyes nacionales a los pueblos indígenas es facultad de las provincias. En la Provincia de Buenos Aires, para abordar la temática de un modelo educativo específico, se trazaron los fines en la ley 13688 (que hemos desarrollado previamente) sobre la Educación Intercultural. El art. 44 de dicha ley provincial establece que la Educación Intercultural "...es la modalidad responsable de impulsar una perspectiva pedagógica intercultural en articulación con la Educación común..." (Ley de Educación Provincial, 2007) cuyo fines son aportar propuestas curriculares para una perspectiva intercultural democrática, bajo el principio de la igualdad y de una educación inclusiva; programas que aseguren el respeto por la diversidad cultural y alienten la comunicación entre distintos grupos culturales; y toda contribución para “(...)asegurar el derecho de los Pueblos Originarios y comunidades migrantes a recibir una educación intercultural $\mathrm{y} / \mathrm{o}$ bilingüe que ayude a preservar, fortalecer y recrear sus pautas culturales, sus lenguas, sus cosmovisiones, sus tradiciones e identidades étnicas (..)"(Ley de Educación Provincial, 2007).

\section{c) Datos estadísticos}

Para entender la problemática, analizaremos datos estadísticos de La Encuesta Complementaria de Pueblos Indígenas, realizada en el año 2004 y 2005, arrojó que 600.329 personas se reconocían pertenecientes y/o descendientes en primera generación de pueblos indígenas. En aquel momento, representaban el 1,7\% del total de habitantes del país. En Argentina, históricamente, han vivido por su flora y fauna una gran diversidad de pueblos indígenas, y se han dispersado por todas las provincias. Se han logrado identificar 46 pueblos, numérica y culturalmente diferentes, distribuidos por todo el territorio nacional, de los cuales 18, por lo menos, mantenían su habla originaria.

El Censo Nacional de Población, Hogares y Vivienda, del año 2010, constituye la mayor fuente de datos para conocer, cuantificar y analizar las características de los pueblos originarios en el territorio de la Argentina. Este censo arrojó resultados más llamativos para el desconocimiento de la población argentina en general, debido a que la composición de la población originaria resulta ser de 955.032 personas, que representaron el 2,38 por ciento del total de la población. 
Para la presente investigación, se utilizó los datos censales de la Provincia de Buenos Aires ${ }^{1}$, donde el 1,9\% de la población de los 24 partidos del Gran Buenos Aires (GBA) se reconoce indígena. Se trata de 186.640 personas sobre un total de 9.916.715 habitantes. Este porcentaje es inferior a la media nacional de 2,4\%. En cuanto a su pertenencia, el 21,2\% de esos 186.640 habitantes se autor reconocieron descendientes del pueblo Guaraní, el 19\% del Toba, el 11,3\% del Mapuche, el 10,5\% del Quechua y el 7,6\% del Diaguita-Calchaquí.

En el censo en cuestión, se realizó un análisis del alfabetismo, la condición de asistencia y el nivel educativo alcanzado en la región, detallado a continuación:

1) Alfabetismo: se estableció parámetros para personas a partir de 10 años en adelante, que arrojó que la tasa de analfabetismo es del 1,3\% en el GBA (una cifra similar para el total de la población en la provincia, que es del 1,4\%).

2) Asistencia escolar: el 35,7\% de la población indígena mayor de 3 años del Gran Buenos Aires asiste a un establecimiento educativo, el $62 \%$ asistió y sólo el 2,3\% nunca asistió. Entre los 63.744 indígenas que asistían en el año 2010 a un establecimiento escolar, el mayor porcentaje estaba en los grupos de 6 a 11 años, 97,8\% (frente al 98,8\% del total de los partidos del GBA); de 12 a 14 años, 96,7\% (frente al 98\%); de 15 a 17 años, 90,5\% (frente al $86,2 \%$ ). En el grupo de 18 a 24 años cae significativamente al 41,2\%, aunque es superior al 35,9\% del total del Gran Buenos Aires. El 37,4\% de indígenas que nunca asistieron a un establecimiento educativo es mayor de 30 años. En este grupo, las mujeres duplicarían a los varones.

3) Nivel Educativo alcanzado: de las 105.496 personas de 20 años o mayor que asistieron a un establecimiento educativo, el $11,2 \%$ tenían el primario incompleto, el $25,9 \%$ primario completo, el $20,5 \%$ secundario incompleto, el $24,4 \%$ secundario completo y el $18 \%$ niveles superiores.

Este número arroja resultados preocupantes, debido a que, según los instrumentos internacionales, leyes nacionales y provinciales que hemos visto, se está muy lejos del ideal de garantizar el derecho a la educación, teniendo en cuenta que una persona de 20 años ya debería estar cursando los niveles superiores. Para dejar aún más en claro la problemática en números, sólo 44.730 personas de 105.496 personas a sus 20 años o más, terminaron siquiera el secundario (lo que representa menos de la mitad).

\section{V) Jurisprudencia}

La Comisión Interamericana de Derechos Humanos es "un órgano principal y autónomo de la Organización de los Estados Americanos (OEA) encargado de la promoción y protección de los derechos humanos en el continente americano" ${ }^{2}$. Por lo tanto, es parte de la labor de la Comisión elaborar denuncias a los Estados Miembros de la Convención Americana para la protección de los derechos humanos y presentar las mismas ante la Corte Interamericana de Derechos Humanos (CIDH).

1 Se utiliza la Provincia de Buenos Aires por la densidad poblacional, ámbito geográfico con áreas urbanas, semiurbanas y rurales, y por el grado de influencia en las políticas públicas.

2 Disponible en: http://www.oas.org/es/cidh/mandato/que.asp 


\section{a) Caso 1: Masacre Plan de Sánchez vs. Guatemala ${ }^{3}$}

En la región central de Guatemala, en el año 1982, alrededor de 268 personas fueron ejecutadas en una masacre desatada por el ejército nacional a los miembros de la Aldea Plan de Sánchez, quienes eran en su mayoría miembros del pueblo maya de ahí y, algunas eran no indígenas residentes de algunas comunidades aledañas. No se realizaron mayores investigaciones ni se sancionaron a los responsables. Ingresa la denuncia a la Comisión la cual accede a investigar los hechos y, en el año 2002, remite el caso a la Corte Interamericana de Derechos Humanos.

Mediante sentencia en el mes de noviembre del año 2004, la Corte determina la responsabilidad internacional del Estado de Guatemala por la violación de numerosos derechos humanos y por la falta de acción en contra de los presuntos autores. Entre las medidas asistenciales, obliga a adoptar al gobierno local el diseño de programas para estudiar y difundir la cultura maya de achí que fue gravemente afectada y, de esa forma, evitar su desaparición. A su vez, debió dotar de personal docente capacitado para la enseñanza intercultural y bilingüe en los niveles primarios, secundarios y otras diversificadas de dichas comunidades.

\section{b) Caso 2: Comunidad indígena Yakye Axa vs. Paraguay ${ }^{4}$}

En el marco de sus facultades, en el año 2003, la Comisión denuncia al Estado de Paraguay por la imposibilidad de una comunidad aborigen conocida como "Yakye Axa" de acceder a la propiedad de sus tierras ancestrales. Opina que la vulneración de ese derecho trajo aparejado a su vez la falta de asistencia alimentaria, médica y sanitaria por parte del gobierno de Paraguay.

Uno de los profesores que daba clases en una escuela de la comunidad presenta sus testimonios a la Corte. Entre ellos, resume claramente la situación que viven los niños y por la cual, no ha podido seguir brindando la educación para fomentar, no solo el desarrollo de la personalidad y aptitudes del alumno, sino también la transmisión de los valores culturales de la comunidad que se veía amenaza. Si un niño no tiene comida ni agua, probablemente se enferme y deje de asistir a clases, ya que sería la menor de sus preocupaciones cotidianas. Lo mismo sucede, dice el testigo, con aquellos niños que no tienen ropa, andan descalzos y con padres desocupados.

Cabe destacar, para entender la precariedad que vivía la comunidad, que la escuela a la que se refería el profesor, se trataba de una casita hecha de palma, con piso de tierra y contaba con dos pizarrones y sillas con pupitres.

Dadas esas circunstancias y otras de igual o mayor tenor, la Corte Interamericana, además de considerar vulnerado el derecho a la educación, decidió dictar sentencia en contra del

3 CIDH, "Masacre Plan Sanchez vs Guatemala",sentencia noviembre del año 2004 disponible en: www.corteidh.or.cr/docs/casos/articulos/seriec_105_esp.pdf

4 CIDH, Comunidad indígena Yakye Axa vs. Paraguay, sentencia 17 de junio 2005,Serie C $N^{\circ} 125$, disponible en: www.corteidh.or.cr/docs/casos/articulos/seriec_125_esp.pdf 
Estado de Paraguay y obligar al Estado a la restitución del territorio tradicional de los miembros de la comunidad, como así también, asumir su responsabilidad por la violación de los derechos a la salud, la identidad cultural, la integridad personal, la libertad de pensamiento y expresión, la protección de la familia y la propiedad privada, entre otros. La Corte dictamina que el gobierno paraguayo debió adoptar medidas para que la comunidad Yakye Axa pueda gozar de una vida digna. Tales medidas son, por ejemplo, garantizar el derecho a una alimentación adecuada, al acceso a agua limpia, a la asistencia médica y sanitaria, y poner el acento en proteger de las enfermedades crónicas a los ancianos de la comunidad; visto y considerando que estos son quienes mejor preservan la identidad cultural de una comunidad y pueden transmitirla oralmente a las nuevas generaciones.

Agrega uno de los petitorios de la Corte que, en materia educativa, se dote a la escuela, antes dicha, en forma inmediata y periódica, de materiales bilingües suficientes para la enseñanza.

En resumen, lo fundamental del fallo es que la Corte Interamericana haya decidido obligar al Estado de Paraguay a la preservación y protección de la comunidad aborigen, señalando que debe abstenerse la actividad estatal de vulnerar sus derechos humanos y, por consecuente, obligar a dictar medidas positivas que permitan el goce de estos derechos. Además, para la presente investigación sobre el derecho a la educación, se debe resaltar la importancia que otorga la Corte a la presencia de una escuela bilingüe para la preservación de los propios métodos de enseñanza y lenguaje de los pueblos originarios.

\section{c) Caso 3: Comunidad Indígena Xákmok Kásek. vs. Paraguay ${ }^{5}$}

El caso se refiere a la responsabilidad internacional del Estado de Paraguay por no haber garantizado el derecho de propiedad ancestral de los miembros de la Comunidad Indígena Xákmok Kásek del Pueblo Enxet-Lengua, lo cual amenazó la supervivencia de sesenta y seis familias y atentó a la desaparición permanente de la comunidad. Ello motivó que los miembros de la comunidad se vieran cada vez más restringidos en el desarrollo de su modo de vida, en sus actividades tradicionales de subsistencia y en su movilidad dentro sus tierras tradicionales.

El conflicto se inició a finales del siglo XIX, y la CIDH recibió la petición en el año 2001; luego de varios años elevó el caso a la Corte IDH. Recién en el año 2010, la comunidad indígena pudo tener sentencia y se destaca que la Corte no se refiere solo al derecho a la propiedad, sino que también alecciona al Estado de Paraguay en materia de derechos humanos.

La Corte realizó observaciones sobre el precario nivel de abastecimiento de agua a la comunidad y sobre la calidad de la misma. Preocupó también a la Corte el suministro de la alimentación y que le corresponde a ella valorar la accesibilidad, disponibilidad y sostenibilidad de la alimentación otorgada a los miembros de la comunidad y determinar si la asistencia brindada satisface los requerimientos básicos de una alimentación adecuada.

5 Corte IDH, Caso Comunidad Indígena Xákmok Kásek. Vs. Paraguay. Sentencia de 24 de agosto de 2010,Serie C No. 214disponible en: www.corteidh.or.cr/docs/casos/articulos/seriec_214_esp.pdf 
Ambos puntos son complementarios del derecho a la salud y a vivir en condiciones dignas. La Corte advirtió al Estado de Paraguay sobre tomar medidas para evitar la deserción escolar de los niños y sobre invertir en mejoras a las condiciones de la escuela a la que asisten los miembros de la comunidad.

La situación de pobreza los llevó a abandonar su propio estilo cultural de vida y necesitaron de las prestaciones básicas por parte del Estado. Aquí un resumen de las palabras de la Corte: “...conforme a los estándares internacionales, los Estados tienen el deber de garantizar la accesibilidad a educación básica gratuita y la sostenibilidad de la misma. En particular, cuando se trata de satisfacer el derecho a la educación básica en el seno de comunidades indígenas, el Estado debe propiciar dicho derecho con una perspectiva etno-educativa. Lo anterior implica adoptar medidas positivas para que la educación sea culturalmente aceptable desde una perspectiva étnica diferenciada..."

\section{VI) Observación General Nº 3}

a) Razón política

El Comité de Derechos Económicos, Sociales y Culturales (CESCR) de las Naciones Unidas, acorde al art. 16 y subs. del PIDESC establece que los Estados Partes deben presentar al Comité informes periódicos sobre la manera en que se ejercitan esos derechos. Inicialmente, los Estados deben presentar informes a los dos años de la aceptación del Pacto y luego, cada cinco años. El Comité tendrá la labor de evaluar los informes para luego expresar sus preocupaciones y recomendaciones al Estado Parte en forma de observaciones finales.

El Comité, en su informe $\mathrm{n}^{\circ} 3$ a la Argentina, le ha manifestado una serie de preocupaciones de las cuales nos interesa, para los fines de la presente investigación, la violación al derecho a la educación y a su interdependencia con otros derechos a la igualdad y no discriminación, a respetar la identidad cultural, entre otros, de las comunidades indígenas. A continuación, la observación:

(...) Preocupa al Comité que a pesar de los esfuerzos hechos por el Estado parte para garantizar el acceso universal a la educación sigan existiendo problemas como el de los niños no incorporados al sistema educativo, el analfabetismo, la repetición de cursos y la deserción escolar, especialmente entre las comunidades indígenas desfavorecidas y marginadas. Además, observa con preocupación que las comunidades indígenas no siempre disfrutan del derecho a una educación bilingüe intercultural (art. 13) (Comité de Derechos Económicos, Sociales y Culturales, N 13).

El Comité recomienda al Estado Parte que aplique eficazmente la legislación vigente para garantizar el derecho a la educación y resolver, en particular, los problemas relacionados con los niños que no se han incorporado al sistema educativo, el analfabetismo, la repetición de cursos y la deserción escolar. Asimismo, lo insta a que continúe sus esfuerzos por eliminar las disparidades existentes entre los distintos grupos de la sociedad y promueva los avances en materia de educación de las provincias y los grupos desfavorecidos y marginados. También, le recomienda queadopte medidas eficaces para garantizar el acceso a los pueblos indígenas a la 
educación intercultural y que vele para que esa educación se adapte a las necesidades específicas de esos pueblos.

Al finalizar el informe, junto con otros petitorios, solicita a la Argentina que difunda las recomendaciones y críticas realizadas a todos los organismos estatales e inclusive a las ONG. De esta forma, trabajando en conjunto, puedan crear medidas para dar cumplimiento a los derechos económicos, sociales y culturales y se puedan notificar en el próximo informe del mes de diciembre del año 2016.

\section{b) Informe del relator}

A fines del año 2011, en su visita a la Argentina, James Anaya, Relator Especial sobre los Derechos de los Pueblos Indígenas, enviado por el Comité del PIDESC, se dedicó a investigar los derechos reconocidos en la Argentina para los pueblos originarios y la efectividad de los mismos. Dicho informe sirvió para la Observación General N³ vista previamente. Para entender el cuadro de situación actual, pretendemos diferenciar los puntos de vista a favor y en contra elaborados en el informe del relator, que fue elevado al Comité sobre el Estado argentino.

A favor:

- Amplio reconocimiento legal del derecho a la educación intercultural bilingüe en la Argentina.

- Diseño de programas de apoyo a la educación intercultural aborigen (diseñado por la INAI) que contempla: becas, tutorías interculturales, alfabetización, reconocimiento y recuperación del conocimiento ancestral de las comunidades, y apoyo para estudiantes de niveles superiores.

- Avance de algunas provincias en la temática, desarrollando políticas que faciliten la educación intercultural bilingüe.

En contra:

- Falta de escuelas en establecimientos rurales, y, sobre todo, la carencia de escuelas del nivel secundario.

- Condiciones de pobreza de las comunidades. Muchos jóvenes se ven obligados a trabajar.

- Falta de capacitación docente para la educación intercultural bilingüe y de maestros que sean, preferiblemente, originarios de comunidades aborígenes.

- Falta de material de estudio idóneo que respete su propia cultura.

- Enseñanza de toda curricula en español para comunidades que lo hablan precariamente. Es necesario que las clases de las materias duras, por lo menos, sean en idioma indígena.

- Situación de vulnerabilidad de las niñas aborígenes. La familia, por su situación económica, da preferencia al niño para asistir a centros educativos y, las mujeres terminan desamparadas buscando su propia subsistencia. 
Para lograr compensar la balanza a favor del derecho a la educación intercultural bilingüe, el Relator da una serie de consejos a la Argentina. Entre estos, menciona el reconocimiento a la labor del INAI, pero, en contrapartida, que su funcionamiento sería más efectivo si el Estado le destinara una mayor partida presupuestaria. Asimismo, le señala al ente que les otorgue a los miembros de los pueblos originarios mayor participación en la toma de decisiones. Al respecto, opina que el Estado, para fomentar la participación, debe crear mecanismos de consulta acorde a los estándares internacionales.

\section{VII) Tribunales de Justicia en Argentina}

En nuestro país, hay un amplio reconocimiento normativo del derecho a la educación, pero encontramos graves falencias en el ejercicio de este derecho, ya que muchas personas se encuentran en una situación de vulnerabilidad tal que les impide acceder a la educación o, si logran hacerlo, no están en condiciones de igualdad. Dentro de estos grupos excluidos, podemos mencionar a los niños en situación de calle o de pobreza extrema, mujeres (discriminación de género), personas con discapacidad y, también, nuestro objeto de estudio, las comunidades aborígenes.

$\mathrm{Al}$ respecto, la autora del libro "Derecho a la educación: el rol de los tribunales de justicia como garantizadores del acceso a la educación en condiciones de igualdad",Liliana M. Ronconi, plantea el trato que suelen tener estos grupos en la Corte Suprema de Justicia de la Nación:

(...) Es posible identificar distintos "test" o "modelos" de razonabilidad. Sin embargo, existen categorías o clases que implican distinciones que prima facie son inconstitucionales por ser discriminatorias: las "categorías sospechosas". Forman parte de dichas categorías, las distinciones basadas en el sexo, la nacionalidad, la raza, la orientación sexual, entre otras.Es así que, verificada la existencia de una categoría sospechosa, el análisis de constitucionalidad debe ser muy estricto y deberá ser el Estado quien justifique la constitucionalidad de dicha diferenciación (inversión de la carga justificadora). Es decir que rige sobre dicha distinción una presunción de inconstitucionalidad, y es el Estado quien debe demostrar por qué está justificada. Así, las consecuencias de que una norma se base en una categoría sospechosa para establecer una distinción son: a) cae la presunción de constitucionalidad de la norma, b) es el Estado quien debe probar que la distinción es estrictamente necesaria para alcanzar un fin imperioso c) se aplica un análisis estricto de razonabilidad(...) (Ronconi, 2015).

Esta doctrina fue aplicada por la Corte Suprema de Justicia de la Nación (en adelante, la CSJN o la Corte) en distintos casos, en los cuales existía una norma que establecía una clasificación fundada en una "categoría sospechosa". En todos estos casos se utilizaba la nacionalidad o el sexo para negar el ingreso de ciertos grupos (extranjeros, mujeres) al empleo 
público, a un establecimiento educativo,a la continuación del ejercicio de la docencia en un establecimiento educativo privado con reconocimiento oficial,a un beneficio social, a un puesto de trabajo.

No hay aún un fallo emblemático de la CSJN sobre la educación intercultural bilingüe, pero si hay amparos en distintas provincias por el vacío estatal en la política educativa. La falta de reclamos judiciales por parte de grupos indígenas, en comparación con la abundancia jurisprudencial de otras temáticas, no se debe al cumplimiento eficaz de sus derechos, sino al desconocimiento de sus derechos constitucionales y otras normas que los tienen como destinatarios.

A partir del reconocimiento de los pueblos originarios en la constitución nacional y provincial, han podido avanzar en reclamo de las tierras que ocupan históricamente ante las órdenes de desalojos. El reclamo por sus tierras es continuamente objeto de litigiosidad, sobre todo por el apoyo de organizaciones no gubernamentales para acceder a la justicia, pero no así en materia de educación.

Hay casos aislados que no llegan a tener la publicidad suficiente, como el de un grupo de estudiantes provenientes de una clínica jurídica de la Universidad de Palermo que, en cooperación con abogados de la Provincia de Neuquén, presentaron un reclamo administrativo al Consejo de Educación Provincial para que se hiciera efectivo el nombramiento de un maestro en el idioma de la comunidad mapuche que habitaba en dicha provincia. Como no tuvieron eco en su reclamo a las autoridades educativas, promovieron una acción de amparo y tuvieron en el Tribunal de Junín de los Andes respuesta favorable, cuya resolución fue obligar al estado provincial a producir el nombramiento de un maestro bilingüe en la comunidad.

A continuación, aporto un caso de la Provincia de Neuquén sobre la inconstitucionalidad de un decreto reglamentario que llegó en manos de la Corte Suprema de Justicia de la Nación.

Confederación Indígena de Neuquén cl Provincia de Neuquén s/ acción de inconstitucionalidad. ${ }^{6}$

La Confederación Mapuche de Neuquén (CMN) realizó una demanda en el año 2002 y planteó la inconstitucionalidad del decreto 1184/02 que había sido firmado ese mismo año por el Gobernador Jorge Sobisch de la Provincia de Neuquén. Lo que plantea la Confederación Mapuche es que el decreto limitaba el reconocimiento de comunidades con requisitos que contradecían la ley nacional y los tratados internacionales de derechos humanos: evaluación de la "identidad étnica", la lengua, tipo de "cultura y organización", "que convivan en un hábitat común" y que sean "por lo menos diez familias".

618 Confederación Indígena del Neuquén c/ Provincia del Neuquén s/acción de inconstitucionalidad

SENTENCIA10 de Diciembre de 2013,CORTE SUPREMA DE JUSTICIA DE LA NACION. CAPITAL FEDERAL, CIUDAD AUTÓNOMA DE BUENOS AIRES, Magistrados: Fayt, Highton, Zaffaroni, Maqueda,Id SAIJ: FA13000190 disponible en: http://www.saij.gob.ar/corte-suprema-justicia-nacion-federalciudad-autonoma-buenos-aires-confederacion-indigena-neuquen-provincia-neuquen-accion-inconstitucionalidadfa13000190-2013-12-10/123456789-091-0003-1ots-eupmocsollaf? 
La demandante apuntó a que, si la provincia regula las personerías jurídicas, obstruiría a las comunidades y sus derechos a la discrecionalidad del gobierno local, contraviniendo de esa forma el artículo 75 de la CN.

Luego de once años de acciones judiciales, en diciembre del 2013, llegó la sentencia de la Corte Suprema de Justicia de la Nación Argentina que declaró la inconstitucionalidad del decreto. Es destacable del fallo, para la presente investigación, la opinión de la Corte al hacer hincapié en el derecho a la auto identificación (no se requiere que el Estado reconozca a una comunidad para que ésta tenga derechos como tal) y la obligación de los Estados a consultar a los Pueblos Originarios al tomar medidas que pudieran afectarlos.

\section{VIII) Conclusión}

A pesar del carácter vinculante de solo dos artículos del PIDESC, la CIDH ha elaborado la estrategia de centrar el litigio y el análisis de posibles violaciones de los derechos económicos, sociales y culturales a partir de su vinculación con los derechos civiles y políticos, como por ejemplo el derecho a la vida. Considero, que a pesar de la discusión doctrinal sobre la interpretación que le han querido otorgar los Estados al art. 26 de la CADH, la Argentina ante cualquier petición individual se vería envuelta en una violación de numerosos derechos humanos. No sería la excepción de estas transgresiones el derecho a la educación y más específicamente, ante los informes negativos, las falencias observadas hacia las comunidades indígenas.

A su vez, se debe respetar el principio de progresividad y no regresividad consagrado en el PIDESC, por lo cual, la normativa local debe siempre avanzar hacia adelante en defensa de los derechos humanos. En el caso de las reglamentaciones de la Provincia Buenos Aires deben adecuarse al piso mínimo de derechos reconocidos en los tratados internacionales, la Constitución Nacional y las leyes nacionales. Hemos analizado el caso de la Provincia de Neuquén en el cual un decreto se devino inconstitucional.

En base a la investigación realizada sobre el primer objetivo planteado considero que ha sido alcanzado el punto de reflexión al que pretendí llegar. La Argentina, en corto plazo, podría tener una sentencia adversa de la $\mathrm{CIDH}$, si las entidades de mayor representatividad de los pueblos originarios demandan a nuestro país ante la $\mathrm{CIDH}$.

Es menester darle entidad a la EIB para salvar la identidad cultural de los pueblos originarios y permitir que las nuevas generaciones aprendan, en las escuelas interculturales bilingües, la historia, costumbres, idioma y creencias de sus antepasados y logren aptitudes para participar del mundo moderno.

En Argentina, la política estatal debe proveer los recursos para que se garantice la modalidad educativa de la EIB por medio de medidas, tales como la creación de nuevos establecimientos educativos en zonas aledañas a las comunidades aborígenes (sobre todo del nivel secundario), la mejora de la formación pedagógica docente y el tratamiento de la lengua nativa en la curricula, entre otras. También, se deben adoptar medidas para evitar la deserción escolar, siendo su principal causa la pobreza y/o enfermedad, brindando prestaciones alimentarias y sanitarias, respectivamente.

Es necesario controlar la política educativa en Argentina y permitir una mayor discusión de fondo de las partidas presupuestarias, ya que es en esto último donde los jueces deberán 
revisar el accionar del Poder Ejecutivo, exigiéndole explicaciones sobre el destino de los recursos económicos a la hora de tomar medidas. Es aquí donde deberían entrar en función la actividad de los poderes judiciales cuando falla el reconocimiento de un derecho a particulares o grupos de personas. Es el juez quién debe citar a los ministros del gabinete pertinente para realizar las preguntas: cuanto, cómo, por qué y para qué.

La falta de jurisprudencia se debe a otras razones que escapan al cumplimiento efectivo del derecho a la educación para los pertenecientes de pueblos originarios, como el desconocimiento de sus derechos para reclamar por qué no pueden ir a la escuela o la falta de enseñanza en la curricula. El acceso a la justicia también se ve limitado por las situaciones de pobreza (falta de alimentación, vivienda, vestimenta) que deben enfrentar muchas comunidades aborígenes que intentan superar el día a día. Otra causal de la falta de casos jurisprudenciales es la denegatoria en materia de recursos judiciales por la estrictez de los poderes de justicia en procesos de crisis económica y/o política.

También considero alcanzado el segundo objetivo planteado. Razono que el rol principal para garantizar el derecho a la educación a los pueblos originarios es de la política educativa que debe asumir el Ministerio de Educación y Cultural ya sea por sí mismo o a través de sus entes descentralizados. En segundo plano, para acceder a la Justicia será fundamental el papel de las organizaciones no gubernamentales de los pueblos originarios para elevar petitorios y en congruencia, con la no aplicación de un rigorismo formal por parte de los jueces al tramitar remedios judiciales.

Para finalizar, sobre el tercer objetivo planteado, reflexiono que, si bien la mirada no es optimista para el desarrollo pleno de la EIB, hay una cantidad de razones que pueden revertir dicha situación. Algunas de las razones que me llevan a pensar positivamente son el grupo numeroso de personas que se reconocen descendientes de grupos originarios en nuestro país, la creciente información de estos grupos sobre los derechos humanos que le pertenecen, y el interés que despierta la temática en algunos sectores de la sociedad.

Quiero compartir la opinión que brinda Gladys Acosta Vargas, Representante de UNICEF Argentina, sobre la Declaración de la ONU sobre los Derechos de los Pueblos Indígenas ${ }^{7}$ : "Esperamos que todos los funcionarios de la administración pública inspirados en los contenidos de la Declaración colaboren con su implementación en las diferentes áreas mediante políticas públicas, decisiones judiciales y leyes, entre otras acciones necesarias para revertir la injusta y discriminatoria situación que viven hoy los pueblos indígenas, particularmente sus niños, niñas y adolescentes, y lograr una mejora sustantiva”.

7 Extraído: Los derechos de los pueblos indígenas explicado para todos y para todas, (C) Fondo de las Naciones Unidas para la Infancia (UNICEF), agosto de 2008, primera edición. 


\section{Bibliografía}

Asamblea General de la ONU (2013). Derechos de los pueblos indígenas. En línea en: http://www.acnur.org/t3/fileadmin/Documentos/BDL/2014/9697.pdf?view=1 (informe del relator)

Área MetodolóGiCA (Dirección Nacional de Información y Evaluación de Calidad Educativa) (2007). La educación que reciben alumnos indigenas. Un aporte a la Educación Intercultural Bilingüe. Ministerio de Educación. Argentina.

ASOCIACIÓN POR los Derechos CIVILES (2008). "Desigualdad en el acceso a la educación en la Provincia de Buenos Aires". El rol de los tribunales de justicia como garantizadores del acceso a la educación en condiciones de igualdad, Revista Latinoamericana de Educación Comparada, pp 66-80 / relec / Año 6 No7 / 2015 / ISSN 1853-3744 / Estudios e Investigaciones, marzo del año 2015.

Censo Nacional de Población, Hogares y Viviendas (2010). Censo del Bicentenario. Instituto Nacional de Estadística y Censos (INDEC) En línea en:

\section{http://www.indec.gov.ar/ftp/cuadros/poblacion/censo2010 tomo2.pdf}

Dalile A. ET AL (2015). Bugdets and Human Rights: Guidilines for litigators, ACIJ.

DiEz M. (2004). Reflexiones en torno a la interculturalidad, Cuadernos de Antropología Social No 19. FFyL - UBA - ISSN: 0327-3776.

DiEz, M. L. (2004). Reflexiones en torno a la interculturalidad. Cuadernos de Antropología Social No 19. En línea en: *http://www.scielo.org.ar/pdf/cas/n19/n19a12.pdf

ENCUESTA COMPlEMENTARIA DE Pueblos IndíGENAS (2004). En línea en: http://www.indec.gov.ar/micro sitios/webcenso/ECPI/index ecpi.asp

JAMES V. (2015). "Los derechos sociales en el Sistema Interamericanode Protección de Derechos Humanos", en el marco del Seminario de grado La Justiciabilidad de los Derechos Sociales. Los estándares internacionales en la justicia bonaerense, La Plata.

MuÑoz, R. (2014). “El “derecho a la educación” como derecho humano”, Revista Los Derechos Humanos en el Derecho Internacional, 1ra. edición, Editorial Ministerio de Justicia y Derechos Humanos de la Nación.

SALVIOLI, F. (2004). "La protección de los derechos económicos, sociales y culturales en el sistema interamericano de derechos humanos”, En Revista N 40; ed. Instituto Interamericano de Derechos Humanos; San José de Costa Rica.

TOMAŠEVSKI, K. (1999). Preliminary report of the Special Rapporteur on the right to education to the UN Commission on Human Rights, submitted in accordance with Commission on Human Rights resolution

1998/33. (2001) Human rights obligations: making education available, accessible, acceptable and adaptable. Right To Education Primers No. 3. Novum Grafiska AB, Gothenburg. (2006) Human rights obligations in education: the 4-A scheme. Nijmegen, Wolf-LegalPublishers.

(2006) The State of the Right to Education Worldwide: Free or Fee - 2006 Global Report. Copenhagen. 
UNICEF (2008). Los derechos de los pueblos indígenas explicado para todos y para todas. Fondo de las Naciones Unidas para la Infancia, primera edición. 